\title{
ABORDAGEM ANTI-REDUCIONISTA EM SAÚDE: UMA CON- TRIBUIÇÃO DAS DISCUSSÕES FILOSÓFICAS NO CONTEXTO DA EDUCAÇÃO EM SAÚDE
}

\author{
Liziane Martins* \\ Valter Forastieri Cova**
}

\begin{abstract}
Resumo
Esse trabalho inicialmente apresenta um estudo introdutório acerca das críticas da epistemologia contemporânea de saúde e sua aplicação ao universo do saber em saúde, procurando explorar algumas contribuições dessas críticas para atenção à saúde biomédica e sua consequente repercussão na Educação em Saúde. Em seguida, apresentamos as quatro abordagens sobre posições explanatórias: atomismo, holismo, reducionismo e antirreducionismo, para entendermos a importância de um embasamento filosófico nas discussões de saúde e suas consequências no ensino. Por fim, tenta-se mostrar as implicações da filosofia na formação dos professores para uma maior compreensão do ensino de Ciências, mais especificamente da educação em saúde.
\end{abstract}

Palavras-chave: Abordagem biomédica. Posições explanatórias. Filosofia. Ensino de ciências.

\begin{abstract}
This paper initially presents an introductory study about the critical of contemporary health epistemology and its application to the universe of knowledge in health, looking to explore some of these critical contributions to biomedical health care and its consequent impact on Health Education. Afterwards, we

\footnotetext{
* Mestre em Ensino, Filosofia e História das Ciências pela Universidade Federal da Bahia (UFBA). Professora do Departamento de Educação da Universidade do Estado da Bahia (UNEB).E-mail: lizimartins@gmail.com

${ }^{* *}$ Mestre em Ensino, Filosofia e História das Ciências pela Universidade Federal da Bahia/ Universidade Estadual de Feira de Santana. Professor do Curso de Pedagogia do Centro Universitário Jorge Amado (UNIJORGE).E-mail: forastieri_biologia@yahoo.com.br
} 
show four approaches about explanatory positions: atomism, holism, reductionism and anti-reductionism, to understand the importance of a philosophical basis in discussions of health and its impact on education. Finally, try to show the implications of philosophy in teacher's education for a better understanding of the Science Education, more specifically in Health Education.

Keywords: Biomedical approach. Explanatory positions. Philosophy. Science education.

\section{Introdução}

A interface entre Educação e Saúde está presente em várias pesquisas sobre o ensino e a aprendizagem de Ciências (COELHO; CONCEIÇÃO; YUNES, 1974; FLAY, 2000; XAVIER; FREIRE; MORAES, 2006). Com ênfase na dimensão pedagógica da saúde, tem-se buscado analisar como determinados temas de saúde são abordados em sala (SUCCI; WICKBOLD; SUCCI, 2005; CARVALHO; SILVA; CLÉMENT, 2007; CARVALHO et al., 2007), quais elementos constituem empecilhos para a aprendizagem sobre saúde (COLLARES; MOYSÉS, 1997), como o conceito de saúde é veiculado nos livros didáticos (MOHR, 1995, 2000), como devem ser as iniciativas de formação de professores voltadas para a educação em saúde (CATALÁN; SALA; BEGUER, 1993), quais são as abordagens de saúde encontradas em livros didáticos de biologia (CARVALHO et al., 2007, 2008, MARTINS; CASTRO, 2009; MARTINS, 2010; MARTINS, SANTOS; EL-HANI, 2012), quais as concepções de saúde de escolares (DAIGLE; HEBERT; HUMPHRIES, 2007), como são os modelos de transposição didática utilizados na formação de profissionais da saúde (CARVALHO; CARVALHO, 2008), entre outros temas.

Diante deste cenário, este trabalho consiste em um estudo introdutório acerca das críticas da epistemologia contemporânea de saúde e sua aplicação ao universo do saber em saúde, procurando explorar algumas contribuições dessas críticas para atenção à saúde biomédica e sua consequente repercussão na educação em saúde. Vale destacar que optamos pelo uso da expressão "educação em saúde", pois se refere às experiências educativas organizadas no ambiente escolar (ou não) com a finalidade de proporcionar oportunidades para a construção de conhecimentos teóricos e práticos em prol da saúde 
individual e coletiva, além de prevalecer como expressão genérica, não sendo necessariamente emblemática de qualquer concepção sobre saúde, política ou educação (VALADÃO, 2004).

A análise das críticas à epistemologia hegemônica na saúde tomada como uma visão insuficiente em saúde tem como um dos marcos de início a fundação da Faculdade de Medicina de Johns Hopkins (Baltimore Maryland), em 1889, e o Relatório Flexner em 1910, que estabelece um enfoque teórico voltado para as causas biomédicas que determinam a doença, diagnosticando e tratando através de conhecimento fragmentado da doença, adquiridos pelas especialidades médicas; uma abordagem pedagógica dividida em ciclo básico e profissionalizante com disciplinas fragmentadas; e um cenário prático, quando oportunizado ao aluno se restringe ao âmbito das especialidades, onde o aluno desenvolverá atividades segmentadas no paciente (LAMPERT, 2004).

Esse modelo de ensino - segundo Brito de Sá (2002), baseado em uma abordagem empírica e reducionista, fortemente apoiada no desenvolvimento laboratorial e tecnológico - conduziu ao surgimento das especialidades médicas e ao desenvolvimento de toda uma cultura e prática médica que hoje é dominante no mundo ocidental. Dessa forma, o panorama da medicina muda passando a utilizar-se de medicamentos padronizados, a depender da tecnologia para curar, com um tratamento visando à supressão da doença e culmina com o surgimento e crescimento de especialidades médicas. Esse modelo de ensino médico repercute diretamente no modelo de ensino escolar, uma vez que é percebida a influência do contexto histórico e social nas práticas dos autores de livros didáticos, professores, gestores escolares.

Essa visão pode ter refletido na corrente teórico-filosófica defendida por Christopher Boorse $(1975 ; 1977)$, que propôs a formulação básica de que "saúde = ausência de doença", já que o número crescente de especialidades médicas almejava buscar o tratamento e a cura das doenças, para se conseguir a saúde. Além disso, essa formulação revelou a grande influência do chamado pensamento cartesiano sobre as concepções de saúde e doença, resultando no modelo que tem sido denominado 'biomédico'. Este modelo constitui o alicerce conceitual da moderna medicina científica, privilegiando o tratamento e a cura do corpo físico em detrimento dos seus caracteres subjetivos (sentimentos, sensações, sintomas), bem como negligenciando a inserção social e ecológica possuída pelos seres humanos. 
É válido enfatizar que uma das principais críticas ao modelo biomédico diz respeito às distorções induzidas pela centralidade na doença (ALMEIDA FILHO; JUCÁ, 2002; BUSS, 2003). Isso ocasiona um tratamento simplório da concepção de saúde, como a mera ausência de doença, o que provoca uma ênfase excessiva na produção de diagnósticos, ao invés de tecnologias que pudessem promover a qualidade de vida, a redução da terapêutica à prescrição medicamentosa e a ênfase numa perspectiva dita curativa, ou no máximo na prevenção das doenças, mas sempre excluindo do foco toda a dinâmica social e subjetiva que os seres comportam (CAMARGO JÚNIOR, 2007).

Objetivando a superação do cenário de incertezas, sobre o que é saúde e quais são os seus determinantes, muitos encontros foram feitos para discutir a saúde em um campo teórico e prático, dentre eles a I Conferência Internacional Sobre Cuidados Primários de Saúde, convocada em 1978 pela Organização Mundial de Saúde (OMS) e pela UNICEF, realizada em Alma-Ata. A partir desta conferência, ganhou proeminência o conceito da promoção de saúde, no qual se dá ênfase à articulação entre o setor de saúde e as políticas sociais, compreendendo-se a saúde como um recurso essencial para o desenvolvimento social e econômico do indivíduo e da comunidade. Esta consideração foi um marco fundamental, levando à elaboração da Carta de Ottawa, em 1986, que listou condições e recursos fundamentais para a saúde, como paz, habitação, educação, alimentação, renda, ecossistema estável, recursos sustentáveis, justiça social e equidade. Seguindo esse direcionamento, com a Declaração de Adelaide, produzida na II Conferência Internacional sobre Promoção da Saúde realizada em 1988, em Adelaide-Austrália, enfatizou-se as políticas voltadas para a saúde (ou políticas públicas saudáveis) e a manutenção das diretrizes já estabelecidas nos encontros anteriores (BRASIL, 2002). É evidente, então, nesta concepção de promoção da saúde a incidência de fatores sociais, econômicos, políticos.

Porém, foi na Suécia, na III Conferência Internacional sobre Promoção da Saúde, em 1991, precedendo a Conferência Mundial sobre o Meio Ambiente realizada no Rio de Janeiro em 1992, que se destacou a interdependência e inseparabilidade entre a ecologia e a saúde (MENDES, 2004). No entanto, poucas mudanças em prol de uma "Saúde para Todos" foram efetivadas e o modelo biomédico continua sendo o predominante.

Assim, o presente trabalho tem como objetivo compreender as dificuldades de uma abordagem holística em saúde, inclusive no contexto 
escolar, conforme defendido pelos opositores da abordagem biomédica, e mostrar a importância de um embasamento filosófico nas discussões sobre as abordagens de saúde e suas consequências para o ensino de Ciências, tendo em vista que o reducionismo e o holismo são posições metodológicas que afloraram na área epistemo-filosófica.

\section{Holismo ou reducionismo: como pensar, agir e ensinar saúde}

Um ponto de partida útil para entendermos às críticas à abordagem biomédica de saúde constitui-se no exame da plausibilidade do reducionismo e do holismo metodológico e das fraquezas dessas doutrinas, já que os opositores desta abordagem atribuem relevância explicativa às "totalidades" que envolvem a saúde, em oposição às explicações individualistas.

No entanto, a fim de compreendermos a essência dessas discussões que envolvem a biomedicina é necessário contrastarmos quatro abordagens sobre posições explanatórias: atomismo, holismo, reducionismo e antirreducionismo, e não simplesmente retratar uma abordagem reducionista em oposição a uma holística.

Ao longo desse debate é comum a omissão de pelo menos duas posições: $\mathrm{o}$ atomismo e $\mathrm{o}$ antirreducionismo, resultando em frequentes mal-entendidos. Assim, os reducionistas com frequência retratam os antirreducionistas como sendo holistas e como se fossem adeptos ao atomismo. De fato, não é difícil encontrarmos confusões entre os expositores dessas concepções, por isso, mapeá-las auxilia no esclarecimento dos pontos distintos dessas metodologias e permite compreender o modo como a saúde vem sendo discutida em sala de aula e o papel dos elementos da filosofia para o ensino de Ciências.

Essas concepções podem ser mapeadas, segundo Levine et al. (1989), através da distinção de duas dimensões: se elas consideram ou não as propriedades e relações entre as entidades sociais agregadas como irredutivelmente explicativas e se elas consideram explicativas ou não as relações entre os indivíduos.

Isto é, se as concepções reconhecem (ou não) a relação de dependência entre as sociedades, grupos, classes, organizações, nações, comunidades etc. como relações que não podem ser compreendidas através de explicações fragmentadas e também se as concepções consideram explicativas (ou não): as propriedades pertencentes a essas entidades como, taxas de inflação, 
formas institucionais, modelos de distribuição de renda; as várias relações estabelecidas entre essas entidades, por exemplo, relações entre sindicatos e empresas, entre nações, entre classes coletivamente organizadas; bem como as propriedades particulares de cada indivíduo como crenças, costumes, habilidades, recursos, quando estabelecem relações com outros indivíduos, como, por exemplo, relação entre patrão-empregado (LEVINE et al., 1989).

O atomismo, para Levine e colaboradores, é uma concepção metodológica que nega o potencial explicativo das relações estabelecidas entre os indivíduos, ou seja, as interações possuídas pelos indivíduos podem ser explicadas por processos causais que operariam de modo estritamente interno aos indivíduos e não dependente das relações estabelecidas entre eles.

É evidente que não reconhecer o papel das interações entre os indivíduos é insustentável, dentro de uma rede de relações em que vivemos (parentes, pais-filhos, patrão-empregado, consumidores, vendedores, médico-paciente etc.), não sendo absurdo, até mesmo afirmar, que essas relações além de explicativas, são irredutíveis, pois ser mãe implica, por exemplo, ter filhos. No entanto, um atomista não ignora as consequências dessas interações, mas discutem-nas como processos causais governados inteiramente por mecanismos intraindividuais.

Já um reducionista compartilha com o atomista a concepção de que uma explicação, em última instância, é redutível a um nível mais elementar, porém reconhece a importância das relações em uma abordagem explicativa, não ignorando das explicações científicas as características relacionais que são irredutíveis.

Por fim, o reducionismo também se difere de duas outras abordagens: o holismo e o antirreducionismo. Enquanto o primeiro assume que tudo que se observa na natureza, pode ser explicado pelas propriedades e relações de fenômenos elementares, as duas outras posições metodológicas defendem a ideia de que as relações são irredutivelmente explanatórias.

Os holistas consideram que as propriedades elementares e suas relações são apenas unidades epifenomenais, ou seja, são produtos que se constituem quando se operaciona o todo, mas que isolados nada explicam.

De qualquer modo, nos parece óbvio que o holismo também recebe muitas críticas, tendo em vista, que eventos singulares estão contidos em complexos. Assim, se não houvesse célula não haveria órgãos, por exemplo, ou se não houvesse indivíduos particulares não haveria sociedades.

O problema, então, reside não em ignorar em uma análise o poder 
explicativo dos níveis fundamentais - conforme proposto pelos holistas mas saber como vincular essa interpretação de nível menor em uma análise constituída por um nível maior.

$\mathrm{Na}$ abordagem antirreducionista se reconhece a importância do plano elementar na análise explicativa de um fenômeno complexo, porém defendese a irredutibilidade nas explicações do plano complexo. Em outras palavras, o antirreducionista admite, ao mesmo tempo, a relevância explanatória das propriedades e relações de partes e todo (EL-HANI, 2000).

Então, após apresentado brevemente as características fundamentais de cada tipo de abordagem, podemos agora questionar: é realmente possível atingir uma atenção a totalidade em uma sociedade formada por seres individuais e com exigências e demandas diferentes? Será que o profissional de saúde não atinge sucesso ou, ao menos, cumpre o seu papel quando descobre o desequilíbrio ou a enfermidade que incomoda ou incomodará o paciente? Mesmo com enfoque em uma particularidade, seja ela corporal ou mental, não é satisfatório quando um profissional médico previne, diagnostica ou trata um indivíduo, conseguindo o restabelecimento da saúde face a algumas disfunções orgânicas e/ou físicas? Pensando no ensino de Ciências: é possível trabalhar esta totalidade em livros didáticos e sala de aula, sem perder o foco de que se trata de um ensino de Biologia? Se esta totalidade se mostra incongruente no campo da saúde, como o professor conseguiria desenvolver estratégias pedagógicas para contemplá-la?

\section{Nem reducionismo, nem holismo: uma contribuição da filosofia para o ensino de saúde}

Diante dessas indagações, cabe afirmar que muitos profissionais obtêm, sim, sucesso profilático e terapêutico, mesmo atentos a particularidades físicas ou biológicas, e que é muito difícil, se não impossível, se ater a um universo multifatorial que influencia a vida das pessoas. Não se pretende valorizar a abordagem biomédica, visto que é certo que questões outras (psicológicas, nutricionais, sociológicas), que não são avaliadas - muitas vezes - em uma consulta médica, são importantes em uma intervenção definitiva e satisfatória em saúde, mas mostrar a inviabilidade de uma atenção integral à saúde.

Outro aspecto que merece ser questionado diz respeito à natureza filosófica dos contra-argumentos biomédicos: estarão sendo empregadas 
adequadamente as posições reducionistas e holistas, nas discussões envolvendo a abordagem biomédica e a saúde, pois recorrer à filosofia nos auxilia entender os elementos principais que permeiam uma problemática que está por detrás de uma posição filosófica.

No entanto, os argumentos filosóficos muitas vezes são evitados quando se aborda as questões de saúde, posição essa contrária às discussões feyerabiana (FEYERABEND, 1981) que sugerem que os argumentos filosóficos não devem ser evitados, mas submetidos a testes de cientificidade prática. Sendo que essas observações devem ser aplicadas especialmente para visões filosóficas sobre explicação, redução e teorias comparativas. Então, por que não aplicá-las no cenário da saúde para trazermos contribuições para o ensino de Ciências? Mais especificamente, por que a Filosofia não se consolida nos cursos de formação de professores, assim como a Botânica e a Zoologia se enraizaram no ensino da Biologia? Ademais um trabalho pedagógico embasado na filosofia contribui para a formação de indivíduos mais críticos e conscientes da diversidade de perspectivas que podem ser lançadas sobre um determinado tema, além de possibilitar uma visão sobre a (des)construção do conhecimento científico, desmistificando o seu empreendimento. Todavia, discussões sobre Filosofia das Ciências no ensino de Ciências, por exemplo, têm sido deficiente; ao mesmo tempo em que a produção de livros didáticos e textos para o ensino básico tem se mostrado escassa (PINHEIRO; WESTPHAL; PINHEIRO, 2005), as experiências da inserção desta discussão não chega à sala de aula (MATTHEWS, 1995; FREIRE JR., 2002), o que reforçam a necessidade de investimentos no âmbito da formação de professores. Severino (1994), por exemplo, salienta que a filosofia cumpre papel essencial na formação dos professores, uma vez que instaura um debate sobre os processos de produção, sistematização e transmissão do conhecimento. Por isso, é recomendado que os professores façam referências à filosofia, bem como a história de suas disciplinas, numa possível sintonia com uma abordagem contextualizada conforme recomendada pela atual legislação brasileira escolar (PINHEIRO; WESTPHAL; PINHEIRO, 2005).

Nessa perspectiva, de hiato entre discussões sobre Filosofia das Ciências e a Educação em Saúde, ao contextualizarmos os argumentos dos críticos à biomedicina e os dos defensores de uma abordagem "holística" em saúde (BUSS, 2000; CASTIEL, 2004; MILLER, 2007), parece-nos evidente que as discussões filosóficas são ignoradas, o que proporciona a presença de alguns equívocos. 
Por exemplo, ao criticar a medicina contemporânea - alegando que ela investiga apenas um órgão biológico, examina apenas o indivíduo, previne apenas doenças, trata apenas com medicações e cura somente o corpo - o que está sendo criticado aparentemente é uma abordagem atomística e não reducionista em saúde, visto que uma análise atomista em saúde insistiria apenas em investigar as características e propriedades intrínsecas ao indivíduo (órgão, sistema biológico, reação medicamentosa, corpo), ou seja, em reconhecer e analisar as entidades explicativas de cunho individual e também aquelas de modo plenamente não relacional.

Todavia, quando se critica a saúde alegando a negligência dos profissionais em considerar outros aspectos que interferem e determinam o estado de saúde, como sociais, econômicos e ecológicos, logo se deve ter cautela ao afirmar ser uma visão "reducionista em saúde", pois o reducionismo concebe, ao menos, a irredutibilidade das propriedades relacionais. Então, uma posição reducionista em saúde consideraria as particularidades que surgem a partir das relações estabelecidas entre os indivíduos, bem como entre ele e o meio, desde que pudessem comprometer o processo de saúde e de doença.

Ademais, uma conduta médica em que cada profissional delimita o seu campo de investigação à luz das suas competências e habilidades em que ele domina e encaminha o paciente a outros especialistas, em busca do auxílio de outros profissionais na realização e interpretação de exames para investigar os supostos danos em particularidades biológicas, aparenta se tratar de uma prática investigativa atomista, e não uma conduta reducionista, pois cada especialista se aterá somente a um microevento e não na análise da existência (ou não) de relações entre eles, mesmo dispondo de outros indicadores teóricos quando submete o indivíduo a investigação clínica.

$\mathrm{O}$ argumento acima pode elucidar o papel das diferentes especialidades médicas, pois cada uma delas busca em seu contexto, explicações científicas, tendo a sua abordagem limitada a determinados fatores investigados. Uma evidência disso é a procura exacerbada por diferentes profissionais, na tentativa de pormenorizar a investigação, tanto por parte das políticas de saúde, como dos seus usuários, que buscam entender a enfermidade apresentada e chegar a um consenso no diagnóstico e no tratamento. Essa atitude desfigura, por sua vez, o discurso da sociedade que defende uma conduta "holística em saúde". 
Imaginemos, agora, que seja possível uma abordagem holística em saúde, na qual o diagnóstico ou tratamento de um paciente seja resultado de um consenso entre diferentes profissionais (médicos, psicólogos, nutricionistas, assistentes sociais, curadores, professores, economistas, políticos, terapeutas, massagistas, fonoaudiólogos, fisioterapeutas etc.) que teriam um único foco, analisar o caso em questão. Será possível chegar a um consenso por meio do dissenso, que certamente estará instalado nessa discussão, já que são profissionais com pressupostos epistemológicos diferentes e por isso reagem de maneira diversa na resolução de um problema? Como se chega a um consenso sem reunir as contribuições de cada profissional, logo, de partes particulares?

Considerando que é necessária uma abordagem global do paciente, ou seja, que se atenham aos diversos fatores que influenciam a saúde, como os fatores econômicos, políticos, sociais, ambientais, o consenso entre as diversas áreas será imprescindível, se ao final, quisermos ter um panorama completo do estado do paciente e possibilitar alguma inferência quanto à etiologia do desconforto ou desequilíbrio em questão. A dificuldade aumenta se pensarmos em didatizar toda esta abordagem global para um livro didático ou mesmo uma aula de Ciências, tornando-se inviável por questão de tempo, espaço e perda do foco na Biologia.

Todavia, não é nossa pretensão, a priori, discutir a inviabilidade de uma abordagem holística no que concerne ao contexto da saúde, muito menos contemplar a sustentabilidade da abordagem biomédica, mas elucidar o quanto é difícil adotar uma postura metodológica global em saúde e, principalmente, mostrar as confusões presente nos argumentos em saúde quando os alicerces filosóficos são ignorados. Isso ressalta a importância de elementos filosóficos no ensino de Ciências e na formação do professor.

As dificuldades frente a uma abordagem holística em saúde são evidentes diante dos poucos recursos disponíveis para a maior parcela da população; da incoerência diagnóstica quando muitos profissionais estão envolvidos; da precariedade social, que inviabiliza a adoção de hábitos saudáveis de vida, que favoreçam uma melhora na qualidade de vida das pessoas etc. Todavia, precisamos reconhecer que assessorar uma pessoa apenas na restauração de um equilíbrio sistêmico biológico, característica do sistema biomédico, não é suficiente, pois a saúde é condição maior que princípios biológicos, químicos ou físicos. 
No entanto, quando se assegura que uma abordagem holística seria a mais adequada em saúde, em oposição à abordagem biomédica, tem-se que levar em consideração que os holistas buscam as propriedades globais, atribuindo nenhum valor explicativo a qualquer propriedade individualizada, ou seja, considerar - em saúde - uma abordagem holística seria conceber a saúde e a doença como "caixas pretas", onde o processo como um todo prevalece sobre qualquer inferência das partes que o compõem. Nessa abordagem, a atenção incidirá apenas nos sinais e sintomas apresentados pelos indivíduos, visto que a estrutura interna dessa caixa é uma incógnita, não-tocável. Portanto, exames diagnósticos, análise das consequências internas a agentes externos, detecção de sinais silenciosos (aqueles sinais que só se manifestam tardiamente), descobertas precoces, relação entre saúde e qualidade de vida etc., seriam inviáveis, pois o foco de investigação dessa abordagem não está em microfenômenos.

Essa forma de investigação, também, poderá ser criticada por não reconhecer a importância da análise dos microfenômenos (partes), já que são elementos contidos no macrofenômeno (todo). E, nem tampouco, admitir a relação de dependência entre parteàtodo e todoàparte. Quando se admite a relação dessa dependência, busca-se compreender as partes, reconhecendo que estas são influenciadas por partes outras. Porém, quando o foco corre para o todo, as partes que o formam (a caixa preta) se relacionam para permitir uma visão global do objeto de estudo, mesmo que estas partes não sejam suficientes para explicar o processo global, por não compreender partes que possam surgir a partir das inter-relações entre as partes.

Nesse momento de discussão em defesa de uma abordagem totalitária em saúde, suscita-nos que, o que se pretende com essa abordagem são condutas antirreducionistas em saúde, e não holísticas, pois o que se quer são profissionais que investiguem os microfenômenos, para posteriormente interpretá-los e sugerir uma conduta profilática e/ou terapêutica global, ao nível de um macrofenômeno, como é o caso da saúde. Em outras palavras, o que se quer é, ao mesmo tempo, a irredutibilidade nas interpretações de fenômenos complexos e a investigação detalhada, ao nível de micromecanismos, dos fenômenos. Sendo exatamente esse o comprometimento da abordagem antirreducionista: a relevância nas descrições das abordagens micro para a compreensão dos macrofenômenos e a irredutibilidade das explicações de nível superior. 
Então, como aderir a uma proposta antirreducionista para o ensino de Ciências, tendo em vista que discutir à saúde numa perspectiva atomista, reducionista ou holística se mostram insustentáveis? Sua adesão é compatível com estratégias pedagógicas que enfoquem nos microfenômenos, comum em discussões da Biologia. Isso porque, o ensino de Ciências pressupõe o tratamento de questões acerca da biologia celular, bioquímica, biofísica, genética, entre outras. Nesta abordagem, os microfenômenos têm relevância explanatória na compreensão de eventos biológicos mais complexos, que repercutem na saúde. Vale enfatizar que nesta proposta as explicações das particularidades da saúde não serão reduzidas para a sua compreensão na Biologia, mas darão suporte ao entendimento do fenômeno "saúde" de modo mais abrangente. Por exemplo, se pensarmos na doença de Chagas, fica preservada a abordagem de microfenômenos ao que concerne o ensino da zoologia do vetor e do parasito, da biologia celular do parasito e dos tecidos do hospedeiro, da interação imunológica entre parasito e hospedeiro e demais fenômenos particulares envolvidos nesta doença.

$\mathrm{O}$ antirreducionismo no ensino de Biologia não perde de vista os macrofenômenos e a importância das explicações macro para o entendimento dos microfenômenos. Como, por exemplo, o uso da ecologia e evolução para a compreensão de fenômenos celulares, bem como de questões políticas, sociais e econômicas que interferem diretamente nas condições de saúde de uma população ou de um indivíduo. Ainda pensando em uma abordagem para a doença de Chagas e adentrando também no campo da Biologia, o macrofenômeno deve ser valorizado com uma discussão ecológica do fenômeno, destacando o parasitismo como uma relação entre populações de organismos e a história evolutiva desta relação. Além disso, traz-se para discussões em sala de aula fenômenos que ultrapassam o contexto estritamente biológico e atingem outras áreas do conhecimento como: desmatamento e políticas ambientais, urbanização e moradia, políticas de saúde nacional.

Diante do exposto, percebemos que a ausência do arcabouço filosófico na educação em saúde gera equívocos que repercutem diretamente na compreensão dos indivíduos sobre saúde. Agrega-se a isso o fato de que a História e a Sociologia, assim como a Filosofia das Ciências auxiliam na superação da crise no ensino de Ciências, uma vez que elas podem humanizar as ciências; tornar as aulas de ciências mais desafiadoras e reflexivas, permitindo o desenvolvimento do pensamento científico; melhorar a for- 
mação do professor, auxiliando o desenvolvimento de uma epistemologia da ciência mais rica e mais autêntica (MATTHEWS, 1995).

Neste contexto, investir na formação dos professores é essencial, pois, como destaca Matthews (1995), um bom professor precisa entender as dimensões cultural e histórica de sua disciplina, conhecer algumas terminologias (causa, lei, explicação, modelo, teoria), bem como entender objetivos que muitas vezes são tratados como conflitantes - "descrever", "controlar", "relacionar". Com uma boa formação em filosofia o professor será capaz, então, de entender porque a abordagem biomédica se sobressai e/ou se mantém nos contexto da saúde, o papel do contexto histórico e social na construção do seu arcabouço teórico e discussões sobre modelo/teoria de saúde se tornam mais claras. Além disso, debates sobre reducionismo, pensamento cartesiano, mecanicismo e biologicismo em saúde passam a ter sentido.

\section{Considerações finais}

Portanto, esse breve texto procurou mostrar até que ponto as críticas quanto à abordagem "reducionista" biomédica de saúde são plausíveis, já que há dificuldades em implementar um cuidado "holístico" em saúde, pois uma investigação médica se alicerça em pilares perceptíveis a outros e não exclusivamente ao paciente (então, é inviável cogitar apenas a investigação dos aspectos subjetivos individuais), a mensurações e quantificações, que, por sua vez, estão respaldados em testes (exames diagnósticos) e verificações (interpretações), ou seja, a medicina contemporânea se fundamenta em técnicas propedêuticas tanto imagética quanto laboratoriais para elucidação do diagnóstico.

Em contra-partida, os argumentos "reducionista e holistas em saúde", aqui criticados, não têm a pretensão de valorizar ou mesmo indicar o modelo no qual se deva ser seguido. O que tentamos foi o seguinte: mostrar que há uma economia, para não sermos radicais ao ponto de dizer ausência, em discussão filosófica, evidenciando que as críticas à abordagem biomédica e o anseio por outra abordagem de saúde (que seria a abordagem holística) não tem o suporte teórico-filosófico que demanda o tema. Nesse sentido, fica evidente que os argumentos contrários à biomedicina são frágeis e não se sustentam, ao ponto de serem incongruentes, quando se critica uma abordagem e propõe-se outra oposta como a solução para o problema. 
Além disso, fica clara a necessidade de inclusão de discussões sobre Filosofia das Ciências ao tratarmos das abordagens de saúde num cenário de educação em saúde. Isso porque a Filosofia empodera os indivíduos, permitindo-os distinguir os diversos argumentos e visões que permeiam a área da educação e da saúde. Ademais, possibilita compreender o empreendimento científico, rompendo com os dogmas da ciência através do entendimento de como se (des)constrói e se refaz uma teoria ou lei, suas influências históricas, sociais, culturais e as controvérsias, dilemas e mudanças no pensamento científico. Todavia, este empoderamento não ocorre frente à crise que vivenciamos na educação atual. Crise esta que poderá ser superada com investimentos na formação de professores, de modo a contemplar a dimensão filosófica e histórica do conhecimento científico.

\section{Referências}

ALMEIDA FILHO, N. de; JUCÁ, V. Saúde como ausência de doença: crítica à teoria funcionalista de Christopher Boorse. Ciência e Saúde Coletiva, Rio de Janeiro, v. 7, n. 4, p. 879-889. 2002.

BRASIL. Ministério da Saúde. Secretaria de Políticas de Saúde. Projeto Promoção da Saúde. As Cartas da Promoção da Saúde, Brasília, 2002, 57p.

BRITO DE SÁ, A. O método clínico: o diagnóstico em situações indiferenciadas; o método clínico centrado no paciente; a Medicina Geral e Familiar baseada na evidência. Lisboa, 2002. Disponível em: <www.aefml.pt/ med0006/aula_de_brito_sa.pdf>. Acesso em: 12 out. 2008.

BUSS, P. M. Promoção da saúde e qualidade de vida. Ciência e Saúde Coletiva, Rio de Janeiro, v. 5, n. 1, p. 163-177. 2000.

. Uma introdução ao conceito de promoção de saúde. In: CZERESNIA, D.; CAMARGO JÚNIOR, K. R. de. Biomedicina, saber e ciência: uma abordagem crítica. São Paulo: Hucitec, 2003.

CAMARGO JÚNIOR, K. R. de. As armadilhas da "concepção positiva de saúde". PHYSIS: Rev. Saúde Coletiva, Rio de Janeiro, v.7 6, n. 1, p. 63-76. 2007. 
CARVALHO, A.; CARVALHO, G. S. de. Eixos de valores em promoção da saúde e educação para a saúde. In: PEREIRA, B. O.; CARVALHO, G. S. de. (Ed.). Actividade fisica, saúde e lazer: modelos de análise e intervenção. Lisboa: Lidel, 2008, p. 195-205.

CARVALHO, G. S.; DANTAS, C.; RAUMA, A.; SILVA, R.; CLÉMENT, P. Historical Analysis of Portuguese Primary School Textbooks (19202005) on the Topic of Digestion. International Journal of Science Education, Londres, v. 29, n. 2, p. 173-193. 2007. Crossef $<<$ http://dx.doi. org/10.1080/09500690600739340>>

. Comparing health education approaches in textbooks of sixteen countries. Science Education International, v. 19, n. 2, p. 133-146, Jun. 2008.

; SILVA, R.; CLÉMENT, P. Historical analysis of portuguese primary school textbooks (1920-2005) on the Topic of Digestion. International Journal of Science Education, Londres, v. 29, n. 2, p. 173-193. 2007.

CASTIEL, L. D. Promoção de saúde e a sensibilidade epistemológica da categoria 'comunidade'. Revista Saúde Pública, São Paulo, v. 38, n. 5, p. 615-622, 2004. Grossef $<<\mathrm{http}$ ://dx.doi.org/10.1590/S0034-89102004000500001>>

CATALÁN, V. G.; SALA, R. M. J.; BEGUER, C. A. La educación para la salud: una propuesta fundamentada desde el campo de la docencia. Enseñanza de las Ciências, Barcelona, v. 11, n. 3, p. 289-296, 1993.

COELHO, H. S.; CONCEIÇÃO, J. A. N.; YUNES, J. Guia curricular de saúde para o ensino de 1. grau. Revista Saúde pública, São Paulo, v. 8, p. 129-144, 1974.

COLLARES, C. A. L.; MOYSÉS, M. A. A. A transformação do espaço pedagógico em espaço clínico: a patologização da educação. Série Idéias - FDE, São Paulo, n. 23, p. 25-31, 1997.

DAIGLE, K.; HEBERT, E.; HUMPHRIES, C. Children's understanding of health and health-related behavior. Education, Alabama, v. 128, n. 2, p. 237-247, Winter, 2007.

EL-HANI, C. N. Níveis da ciência, níveis da realidade: evitando o dilema holismo/reducionismo no ensino de ciências e biologia. 2000. 391f. Tese (doutorado) - Faculdade de Educação da Universidade de São Paulo, São Paulo. 2000. 
FEYERABEND, P. K. Realism, rationalism and scientific method: Philosophical papers, New York: Cambridge University Press, 1981a. v.1. Crossef $<<\mathrm{http} / / /$ dx.doi.org/10.1017/CBO9781139171526>>

FLAY, B. R. Approaches to substance use prevention utilizing school curriculum plus social environment change. Addictive Behaviors, Amsterdam, v. 25 , n. 6 , p. $861-885,2000$. Gossef $<<\mathrm{http}: / /$ dx.doi.org/10.1016/S03064603(00)00130-1>>

FREIRE JR, O. A relevância da filosofia e da história das ciências para a formação de professores de ciências. In: SILVA FILHO, W. J. et al. Epistemologia e Ensino de Ciências. Salvador: Editora Arcádia, 2002. p. 51-92.

LAMPERT, J. B. Na transição paradigmática: o que o paradigma da integralidade atende que o paradigma flexneriano deixou de lado. Cadernos $A B E M$, Rio de Janeiro, p. 23-25, 2004.

LEVINE, A.; SOBER, E.; WRIGHT, E. O. Marxismo e individualismo metodológico. RBCS, Rio de Janeiro, v. 4, n. 11, p. 57-70, Out. 1989.

MARTINS, L.; CASTRO, T. A. Abordagens de saúde em um livro didático de biologia largamente utilizado no ensino médio brasileiro. In: encontro de pesquisa em educação em ciências, 7., 2009, Florianópolis. Anais... Belo Horizonte, 2009. v. 1.

MARTINS, L. Saúde no contexto educacional: as abordagens de saúde em um livro didático de biologia do ensino médio largamente usado. 2010. 173f. Dissertação (Mestrado em Ensino, Filosofia e História das Ciências) - Instituto de Biologia, Universidade Federal da Bahia, Salvador, 2010.

MARTINS, L.; SANTOS, G. S.; EL-HANI, C. N. Abordagens de saúde em um livro didático de biologia largamente utilizado no ensino médio brasileiro. Investigações em Ensino de Ciências (Online), Porto Alegre, v. 17, p. 249-283, 2012.

MATTHEWS, M. R. História, filosofia e ensino de ciências: a tendência atual de reaproximação. Caderno Catarinense de Ensino de Física, Florianópolis, v. 12, n. 3, p. 164-214, Dez. 1995. 
MENDES, I. A. C. Desenvolvimento e saúde: a declaração de alma-Ata e movimentos posteriores. Revista Latino-Americana de Enfermagem, Ribeirão Preto, v. 12, n. 3, p. 447-448, mai./jun. 2004. Disponível em: <http:// www.eerp.usp.br/rlaenf>. Acesso em: 20 out. 2007.

MILLER, G. Ecological approach to school health promotion: review of literature. Disponível em: <http://www.schoolhealthresearch.org/downloads/miller.pdf $>$. Acesso em: 8 Fev. 2007.

MOHR, A. A saúde na escola: análise de livros didáticos de $1^{\mathrm{a}}$ a $4^{\mathrm{a}}$ séries. Cadernos de Pesquisa da Fundação Carlos Chagas, São Paulo, v. 94, p. 50-57, 1995. . Análise do conteúdo 'saúde' em livros didáticos. Ciência \& Educação, Bauru, v. 6, n. 2, p. 89-106, 2000.

PINHEIRO, T. C.; WESTPHAL, M.; PINHEIRO, T. de F. Mario Bunge e a utilização da história e da filosofia da ciência no ensino de ciências: um enxerto histórico. In: encontro nacional de pesquisa em educação em ciências, 5., Bauru. [Anais eletrônicos...] Bauru, 2005. 1 CD-Rom.

SEVERINO, A. J. Filosofia da educação: construindo a cidadania. São Paulo: FTD, 1994.

SUCCI, C. M.; WICKBOLD, D.; SUCCI, R. C. M. A vacinação no conteúdo de livros escolares. Revista da Associação Médica Brasileira, São Paulo, v. 51 , n. 2, p. 75-79, 2005. Crossef $<<\mathrm{http}: / /$ dx.doi.org/10.1590/S0104$42302005000200013>>$

VALADÃO, M. M. Saúde na escola: um campo em busca de espaço na agenda intersetorial. 2004. 154 f. Tese (Doutorado em Serviços de Saúde) - Departamento de Prática de Saúde Pública, Universidade de São Paulo, São Paulo, 2004.

XAVIER, M. C. F.; FREIRE, A. S.; MORAES, M. O. A nova (moderna) biologia e a genética nos livros didáticos de biologia no ensino médio. $\mathrm{Ci}$ ência \& Educação, v. 12, n. 3, p. 275-289, 2006. Crossef $<<$ http://dx.doi. org/10.1590/s1516-73132006000300003 >>

Data de registro: $16 / 03 / 2014$

Data de aceite: $22 / 10 / 2014$ 